\title{
BMP signaling in dermal papilla cells is required for their hair follicle-inductive properties
}

\author{
Michael Rendl, Lisa Polak, and Elaine Fuchs ${ }^{1}$ \\ Howard Hughes Medical Institute, Laboratory of Mammalian Cell Biology and Development, The Rockefeller University,
} New York, New York 10021, USA

Hair follicle (HF) formation is initiated when epithelial stem cells receive cues from specialized mesenchymal dermal papilla (DP) cells. In culture, DP cells lose their HF-inducing properties, but during hair growth in vivo, they reside within the HF bulb and instruct surrounding epithelial progenitors to orchestrate the complex hair differentiation program. To gain insights into the molecular program that maintains DP cell fate, we previously purified DP cells and four neighboring populations and defined their cell-type-specific molecular signatures. Here, we exploit this information to show that the bulb microenvironment is rich in bone morphogenetic proteins (BMPs) that act on DP cells to maintain key signature features in vitro and hair-inducing activity in vivo. By employing a novel in vitro/in vivo hybrid knockout assay, we ablate $B M P$ receptor $1 a$ in purified DP cells. When DPs cannot receive BMP signals, they lose signature characteristics in vitro and fail to generate HFs when engrafted with epithelial stem cells in vivo. These results reveal that BMP signaling, in addition to its key role in epithelial stem cell maintenance and progenitor cell differentiation, is essential for DP cell function, and suggest that it is a critical feature of the complex epithelial-mesenchymal cross-talk necessary to make hair.

[Keywords: Stem cell niche; hair follicle induction; hair follicle formation; dermal papilla; cell fate specification; mesenchymal-epithelial interactions]

Supplemental material is available at http://www.genesdev.org.

Received September 10, 2007; revised version accepted December 10, 2007.

Adult stem cells balance self-renewal and differentiation by receiving cues from their microenvironment. This communication between multiple cell types occurs in specialized anatomical structures, or niches, that provide the spatiotemporal signals for stem cells to maintain normal tissue homeostasis. The stem cell niche concept originated $>30$ years ago (Schofield 1978), but was largely unexplored until recent work in Drosophila germ cells (Xie and Spradling 2000; Lin 2002). In mammals, similar concepts have been proposed for intestinal epithelium, bone marrow, and hair follicles (HFs) (Moore and Lemischka 2006).

In intestinal epithelium, stem cells reside at the base of crypts tucked away from the cell surface, but surrounded by mesenchymal cells from which instructive signals are thought to emanate (for reviews, see Reya and Clevers 2005; Moore and Lemischka 2006; Blanpain et al. 2007). In the bone marrow, hematopoietic stem cells are among the best-characterized stem cell populations; however, their microenvironmental relationship with

${ }^{1}$ Corresponding author.

E-MAIL fuchslb@rockefeller.edu; FAX (212) 327-7954.

Article is online at http://www.genesdev.org/cgi/doi/10.1101/gad.1614408. niche stromal cells and osteoblasts is just beginning to emerge (Calvi et al. 2003; Zhang et al. 2003; Katayama et al. 2006; Perry and Li 2007; Sacchetti et al. 2007; Walkley et al. 2007a,b). In the HF, keratinocyte (KC) stem cells are induced by specialized mesenchymal cells to develop HFs, a process that is cyclically replicated throughout life (Jahoda et al. 1984; Cotsarelis et al. 1990; Hardy 1992). Despite the importance of stem cells for regenerative medicine, however, little is known about the features of these crucial mesenchymal cells and how they maintain their inductive and supporting properties.

During embryonic HF formation, epithelial-mesenchymal interactions promote the specification and clustering of specialized dermal cells, called dermal papilla (DP) cells, that in turn transmit cues to multipotent skin epithelial stem cells to initiate HF morphogenesis (for reviews, see Millar 2002; Cotsarelis 2006; Fuchs 2007). Continuous reciprocal communication then leads to the downgrowth of epithelial cells, which engulf the DP to form a bulb-like niche at the base of the growing HF (Supplemental Fig. S1). The mature HF bulb contains a core of DP cells surrounded by a basement membrane (BM), which is contiguous with the BM that forms the boundary between the dermal sheath and the HF outer 
root sheath (ORS). On the inner side of the BM, a small group of pigment-producing melanocytes $(\mathrm{Mc})$ resides just above the DP, while the proliferating epithelial matrix progenitors $(\mathrm{Mx})$ at the bulb base generate the differentiating inner root sheath (IRS) and outgrowing hair shaft that receives the pigment. Throughout the hair growth phase, the DP acts as a signaling center for the epithelial-mesenchymal cross-talk that regulates the balance between Mx cell proliferation and hair production (Schmidt-Ullrich and Paus 2005; Alonso and Fuchs 2006).

In the adult, HFs undergo cycles of destruction, rest, and regeneration. During the destructive phase, the lower two-thirds of the HF degenerate, causing the dying epithelial strand to regress. The intact DP moves upward until it comes to rest just below the HF bulge, where the follicle epithelial and Mc stem cells reside (Cotsarelis et al. 1990; Nishimura et al. 2002). The DP is believed to play a pivotal role in instructing these stem cells to initiate the next cycle of HF formation and hair growth (Blanpain et al. 2004; Morris et al. 2004; Tumbar et al. 2004).

In the past decade, considerable progress has been made in elucidating signaling pathways, particularly bone morphogenetic proteins (BMPs) and Wnts, that are required for maintaining epithelial stem cell features and their proliferative matrix cell progeny during HF formation in the embryo and the adult (for review, see Fuchs 2007). Additionally, FGF signaling has been defined as a part of the epithelial-mesenchymal cross-talk, as matrix cells display the FGFR2 receptor IIIb subunit, while its main ligands, FGF7 and FGF10, are expressed by DP cells (Guo et al. 1996; Grose et al. 2007; M. Rendl and E. Fuchs, unpubl.). Much less is known about signaling pathways that operate in DP cells, enabling them to respond to cues from their microenvironment and stimulate HF epithelial progenitors.

Progress in elucidating key features of the DP has been hampered by the small number of DP cells and the difficulty in purifying them. A breakthrough was achieved when Morgan and coworkers (Kishimoto et al. 1999, 2000) used fluorescence-activated cell sorting (FACS) to enrich DP cells, enabling them to exploit a limited knowledge of the complex DP microenvironment. They showed that DP cells lose their hair-inducing properties when placed in culture and that the inductive ability could be prolonged by exposing the cells to Wnt3a but not Shh, two factors that were expressed by epithelial cells in the hair bulb (Kishimoto et al. 2000). Whether DP cells respond to BMPs, FGFs, or other growth factors that are also expressed by the DP niche remains largely unknown.

Recently, we developed new FACS strategies to both enhance purification of DP cells and also isolate cells of the hair bulb microenvironment: $\mathrm{Mx}$ and ORS cells, Mc, and a population enriched in dermal fibroblasts. This enabled us to transcriptionally profile the niche and define molecular signatures characteristic for the DP and each of its surrounding cell types (Rendl et al. 2005). We have now addressed how the DP molecular signature changes when cells are placed in culture. With comprehensive knowledge of the DP signature receptors and the growth factors expressed in the niche microenvironment, we explored systematically the signaling pathways responsible for maintaining molecular signature features in vitro. We uncovered an unexpected role for BMP signaling in this process and used a novel DP-specific in vitro/in vivo hybrid knockout assay to document a role for BMP signaling within the DP that appears to be important for its ability to induce HF formation in reconstituted skin in vivo. When taken together with the established role of BMP signaling in follicle epithelial stem cells and Mx cells, our findings underscore the importance of this pathway in the epithelial-mesenchymal cross-talk involved in HF formation. These findings suggest a molecular understanding for the intriguing epithelial-mesenchymal switch in BMP mRNA expression observed more than a decade ago (Lyons et al. 1990; Vainio et al. 1993).

\section{Results}

Unveiling the importance of BMP signaling in regulating the molecular identity of DP cells

To explore what constitutes the hair-inducing cell fate of DP cells, we evaluated our previously acquired hair bulb molecular signatures for surface receptors and growth factors that could play a role in conferring DP cell fate specification in hair induction and growth. Out of 184 annotated DP signature genes, eight were receptors and eight were growth factors. An additional nine receptors and six growth factors were expressed by DP and also by other hair bulb cell types, while five further growth factors, including Wnt $3 a$ and Shh, surfaced as potential DP signature receptor ligands produced by other hair bulb cell types but not DP (Table 1).

Table 1. Ligands and receptors in the DP and hair bulb signatures

\begin{tabular}{lllll}
\hline \multirow{2}{*}{$\begin{array}{l}\text { DP } \\
\text { receptors }\end{array}$} & \multicolumn{4}{c}{ Putative ligands } \\
\cline { 2 - 5 } & DP & Mx & ORS & Other \\
\hline Acvr1 & Bmp4 & Bmp2 & Bmp7 & Egf \\
Acvr2 & Bmp6 & Bmp4 & Pdgfb & Fgf2 \\
Bmpr1a & Bmp7 & Bmp7 & Tgfb1 & Gdnf \\
Egfr & Fgf10 & Nog & Tgfb2 & Igf \\
Fgfr1 & Fgf7 & Pdgfa & & Ngf \\
Fgfr2 & Gdf10 & Shh & & Pdgfa \\
Fzd2 & Hhip & Tgfb1 & & Prl \\
Gfra1 & Inhba & Tgfb2 & & Pth \\
Igf2r & Nog & Wnt3a & & RA \\
Ngfr & Ost & Wnt5a & & Tgfb1 \\
Pdgfra & Pdgfa & & & Tgfb2 \\
Pdgfrb & Tgfb2 & & & \\
Prlr & Wif1 & & & \\
Ptch & Wnt5a & & & \\
Pthr1 & & & & \\
Tgfbr1 & & & \\
Tgfbr2 & & & \\
\hline
\end{tabular}


To directly test the role of these pathways, we performed an in vitro screen in which we used FACS to freshly isolate pure DP cells, which in culture lose their hair-inducing activity within the first passages (Kishimoto et al. 2000). We then asked whether ligand-mediated pathway activation could preserve DP's molecular identity in vitro and prolong hair-inducing capacity in vivo (Fig. 1A). We tested alkaline phosphatase (AP) expression as our initial readout, since it is both a wellestablished DP marker (Fig. 1B; Handjiski et al. 1994) and also among the most highly expressed genes within the DP signature (Akp2) (Rendl et al. 2005). Nearly all freshly isolated DP cells expressed AP activity, and during the first few days in culture, the majority remained
A

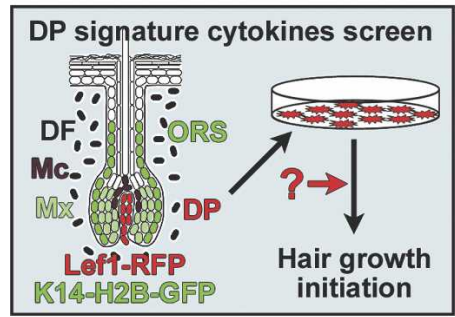

C
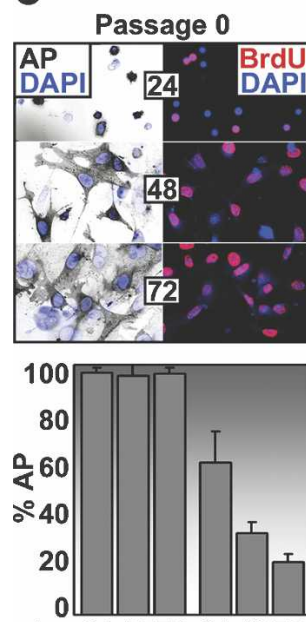

hrs $244872 \underline{244872}$ hrs $244872 \underline{244872}$

Passage 0

E

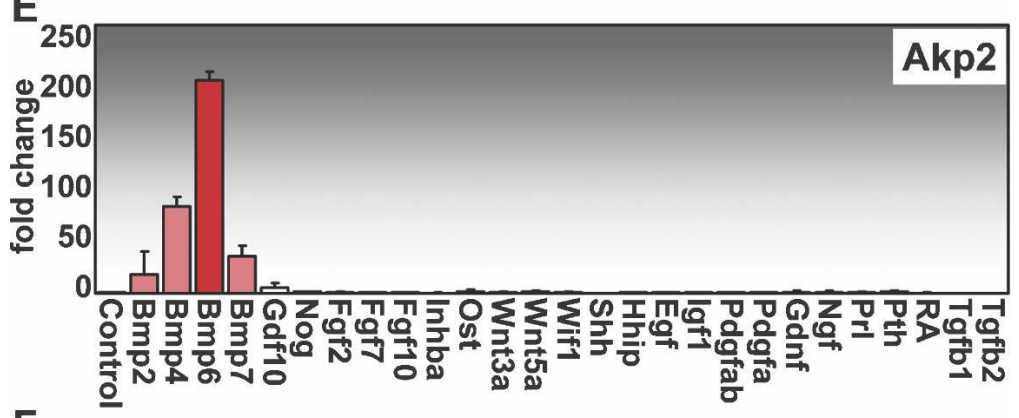

F

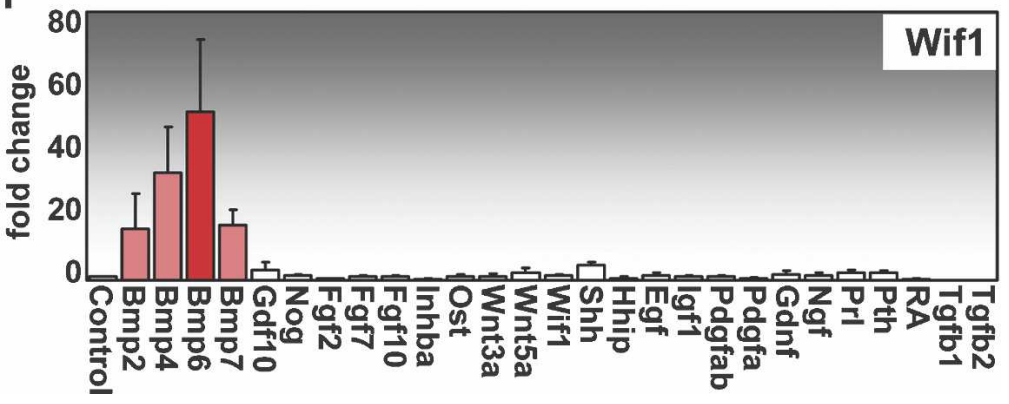

B

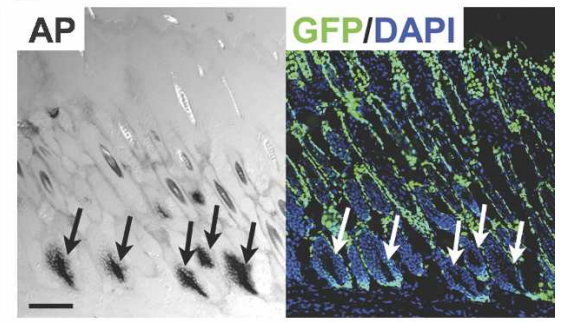

D
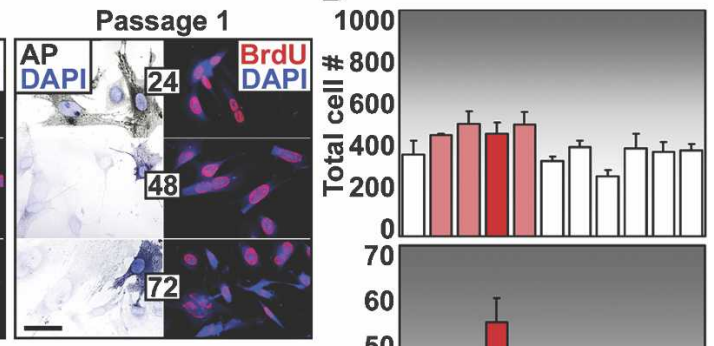

60

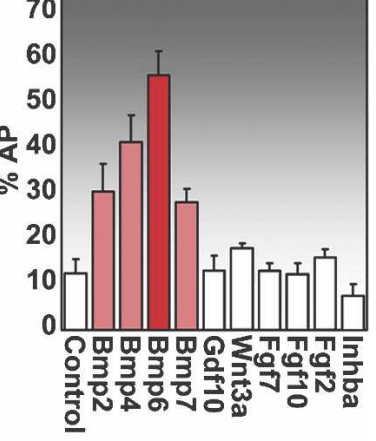

Akp2

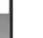

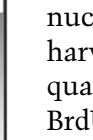
the times indicated and as $\mathrm{BrdU}(+) / \mathrm{AP}(+)$ (right graph). Bar, $50 \mu \mathrm{m}$. Error bars indicate SD. (D) BMP6-mediated maintenance of AP activity in cultured DP cells. DP cells were cultured in the presence of a subset of growth factors/cytokines expressed by the DP niche and for which the DP possesses corresponding surface receptors. The relative effects on cell proliferation and maintenance of AP activity were quantified as in $C$. Error bars indicate SD of triplicate experiments. $(E)$ Largescale screen for DP niche growth factors/cytokines affecting AP gene expression $(A k p 2)$ in DP cells. Note that of the 27 factors tested, only BMPs maintained $A k p 2$ at the mRNA level as detected by realtime PCR. Error bars indicate SD of duplicate experiments. $(F)$ Screen results of Wif1 expression. A similar pattern of BMP-mediated maintenance was found for the DP signature gene Wif1 by real-time PCR. Error bars indicate SD of duplicate experiments. 
Rendl et al.

positive (Fig. 1C). However, after the first passage, DP cells began to lose AP expression (Fig. 1C, left graph), and by the second passage, $<5 \%$ were AP-positive (data not shown). When primary DP cells were colabeled with bromodeoxyuridine (BrdU), 80\%-90\% of DP cells were proliferative in culture (Fig. 1C, right graph). This number remained high with passage, despite a steady decline of BrdU/AP double-positive cells (Fig. 1C, red bars).

We next tested signature growth factors of major signaling pathways to assess whether they affected proliferation and/or could prevent the loss of AP activity (Fig. 1D). None of the ligands caused gross alterations in either morphology (data not shown) or proliferation of the cultures (Fig. 1D, top graph). However, four different BMPs had a marked effect in maintaining AP activity in DP cells in vitro (Fig. 1D, bottom graph). Real-time PCR detection of AP gene expression (Akp2) showed that the BMP-mediated effects were at the mRNA level (Fig. 1E). Moreover, the effects on $A k p 2$ expression were highly specific to members of the BMP family, since 23 other factors-including SHH, WNTs, FGFs, and others that are expressed within the DP microenvironment-scored negatively in this assay. The effects of BMP were not limited to $A k p 2$ as a similar BMP-specific pattern of regulation was also observed when we analyzed the mRNA expression levels of another DP signature gene, Wif1 (Fig. 1F). Moreover, the BMP effects extended to a third DP signature gene, $A l \times 4$, and the effects observed were dose-dependent with a sensitivity extending down to $25-50 \mathrm{ng} / \mathrm{mL}$ (Supplemental Fig. S2A). Since the potential importance of BMP signaling on DP cells has not been explored previously, and since BMP6 had the most pronounced effects of the BMPs, we concentrated on BMP6 for most of our subsequent studies.

To determine the extent to which other DP signature features are lost upon culture and the degree to which BMPs can alleviate these effects, we treated DP cells with BMP6 and performed semiquantitative PCR on a broad range of DP signature genes expressed by freshly isolated DP cells prior to culture (Rendl et al. 2005). As shown in Figure 2A, many DP signature features were retained in vitro. Notable examples included Fgf7 and Fgf10 encoding key DP factors that are essential for Mx cell maintenance (Guo et al. 1996; Grose et al. 2007), and in many of these cases the genes were not influenced by exogenous BMP6. In contrast to Fgf7 and Fgf10, some signature genes were markedly down-regulated. This included not only $A k p 2$ and Wif1, but also genes encoding
Figure 2. Maintenance of molecular signature features of cultured DP cells by BMP signaling. $(A)$ FACSorted DP cells from P4 K14-H2B-GFP/Lef1-RFP mice were cultured in medium $\pm 400 \mathrm{ng} / \mathrm{mL}$ BMP6. Semiquantitative RT-PCRs were conducted on a battery of DP signature genes, and data for the two most relevant PCR cycle numbers are shown. DP signature genes that are either enhanced (red, up arrow) or diminished (green, down arrow) upon BMP6 treatment are highlighted. Note that Nog (Noggin) is up and only $B m p 6$ is decreased, suggesting a feedback circuit. $(B, C)$ Testing for AP activity and DP signature gene maintenance by retroviral expression of $B m p 6, B m p r 1 a^{*}$, and Wnt $3 a$. DP cells were infected with expression constructs for $B m p 6$, the constitutively active form of $B m p r 1 a^{*}$ or Wnt3a. (B) AP activity (green; counterstain is DAPI in blue) was detected (left) and quantified (right). Bar, $50 \mu \mathrm{m} .(C)$ Realtime PCR of DP signature genes are presented as fold change relative to control. Vim (Vimentin) expression served as control. Error bars indicate SD of duplicate experiments.
A
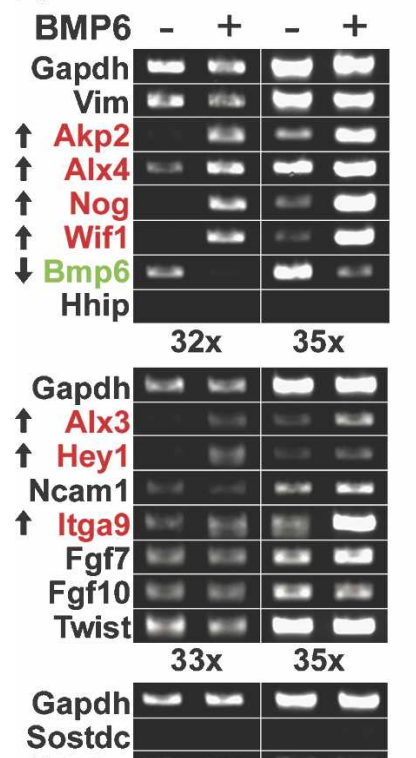

Sostdc

Pdgfra $\infty \backsim \infty$

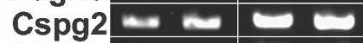

Wnt5a

Trps1 as e

Sox18
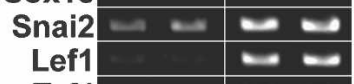

Tcf4

Bmp4

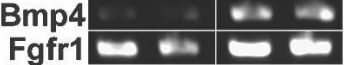

Ptch1

Fst $\approx \infty 0$

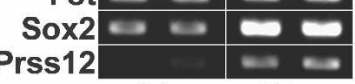

$34 x$

$37 x$
B
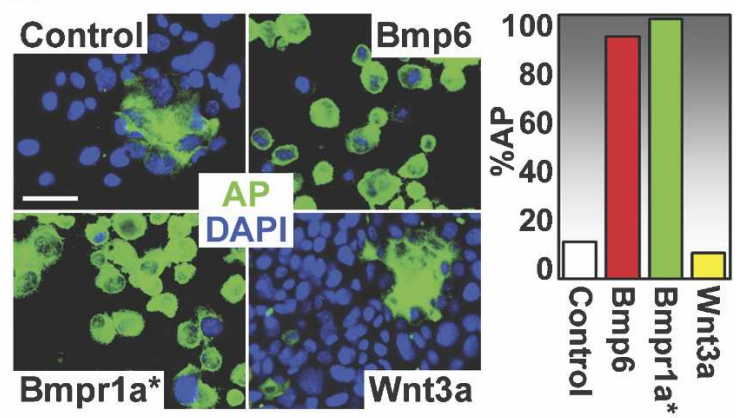

C
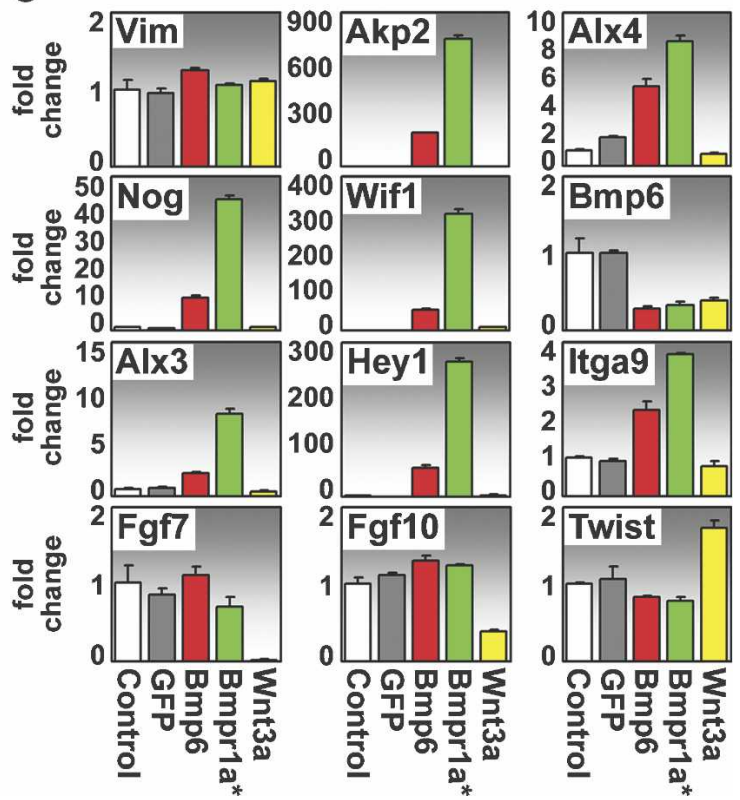
Hhip, a Sonic hedgehog inhibitor; Hey1, a downstream target of Notch signaling; and the secreted BMP receptor inhibitors Nog (Noggin) and Sostdc1 (ectodin) (Fig. 2A). Some of these, like Hhip and Sostdc1, were not maintained by exogenous BMP6. Others, including Akp2, Wif1, Alx4, Hey1, and Nog, were up-regulated by BMP6. Interestingly, Bmp6 gene expression itself was downregulated, suggesting that $B m p 6$ is regulated by a negative feedback loop.

The effects of BMP6 regulation manifested early during culture initiation and without changes in proliferation and cell morphology (Supplemental Fig. S2B). A similar range of DP signature gene regulation was found with BMP2, BMP4, and BMP7 (Supplemental Fig. S3A). Taken together, these data suggest that DP cells in culture lose certain features of their molecular identity that BMP signaling can restore. Interestingly, these DP signature genes regulated by BMP signaling were not similarly affected by SHH, WNTs, FGF2, FGF7, FGF10, or other growth factors (Fig. 1E,F; data not shown). This was surprising for factors such as FGF2, as DP cells express Fgfr1 and Fgfr2IIIc encoding its receptors.

To further probe the significance of BMPs on the DP signature, we retrovirally overexpressed $B m p 6$ and a constitutively active form of the BMP receptor 1a (Bmpr1 $\left.a^{*}\right)$ (Akiyama et al. 1997). While overexpression of Bmp6 in DP cells would mimic endogenous expression, overexpression of the active receptor would bypass the need for cytokine activation and suggest that signaling occurs through this receptor. We also tested $W n t 3 a$, expressed by hair bulb epithelial cells and known to extend hairinducing activity of cells enriched for DP (Kishimoto et al. 2000). All viruses infected with comparable efficiency based on GFP expression derived from the bicistronic expression vectors, and in each case, the expected coding sequences were detected (Supplemental Fig. S4A). Additionally, Wnt3a functionality was verified by nuclear translocation of $\beta$-catenin and by activation of the Wnt reporter TOPflash (Supplemental Fig. S4B; Korinek et al. 1998).

As shown in Figure 2B, overexpression of Bmp6 and Bmpr1 $a^{*}$ both led to robust maintenance of AP activity that was even stronger when compared with BMP6 cytokine treatment. Similarly, Bmp6-mediated and Bmpr1 $a^{*}$-mediated up-regulation of gene expression was also observed for a number of DP signature genes (Fig. 2C). In contrast, Wnt3a expression did not influence AP activity or expression of most BMP-regulated genes, although it did activate expression of Twist, a known Wnt target gene (Howe et al. 2003) that is also part of the DP signature (Fig. 2C). These data extended our earlier findings (Fig. 1D,E) and indicate that BMP signaling maintains parts of the DP signature that are not regulated by Wnt signaling.

\section{Evidence for BMP signaling in vivo and its regulation in vitro}

Given our observations thus far, we turned to addressing whether BMP signaling occurs in the DP in vivo and whether the prerequisites for such signaling are met in vitro. Bmp2 and Bmp4 are both expressed in the hair matrix, while $B m p 4$ and $B m p 6$ are expressed in the DP (Fig. 3A; see also Kulessa et al. 2000; Rendl et al. 2005). Bmpr1a is expressed in all different hair bulb populations, although it was especially prominent in the DP (Fig. 3B; see also Botchkarev and Sharov 2004; Rendl et al. 2005). Thus, the potential for both autocrine and paracrine regulatory loops exists within the microenvironment of the bulb. When we evaluated the array data for all BMP ligands and inhibitors expressed in the hair bulb microenvironment, the complexity of possible negative and positive BMP signaling loops was even greater than those emerging from the signature $B M P$ genes alone (Supplemental Fig. S5).

The outcome of BMP signaling is cytoplasmic phosphorylation of SMAD1/5/8, enabling their interaction with SMAD4 and translocation to the nucleus, where their target genes are then transcribed (Massague et al. 2005). As judged by specific immunofluorescence staining for phosphorylated (active) SMAD1, BMP signaling was active in the DP (Fig. 3C; see also O'Shaughnessy et al. 2004). Moreover, within the DP (Fig. 3C, arrows), a gradient of anti-pSMAD1 staining was observed, suggesting the strongest signaling in the cells closest to the differentiating cells of the hair and IRS (Fig. 3C, arrowheads), where BMP signaling is known to be required. Marked by c-Kit (KIT), Mc also exhibited intense pSMAD1 labeling in the upper DP niche. Conversely, the weakest anti-pSMAD1 labeling was at the base of the DP adjacent to the matrix cells, where, intriguingly, BMP inhibition is thought to be required for maintaining matrix character (Kulessa et al. 2000; Kobielak et al. 2003; Andl et al. 2004).

In vitro, BMPs also stimulated nuclear phosphoSMAD1 localization, substantiating the effects of exogenously added BMP6 on DP cells (Fig. 3D). Since the DP signature includes a plethora of negative BMP regulators (Rendl et al. 2005), and since some of these inhibitors are also expressed by other hair bulb cells (see Supplemental Fig. S5; Kulessa et al. 2000), we examined the effects of exogenously added Noggin (NOG). In all cases tested, DP signature genes that were strongly up-regulated by recombinant BMP6 were also potently inhibited by NOG (Fig. 3E). Interestingly, while BMP6 resulted in a dosedependent down-regulation of $B m p 6$, it caused an upregulation of Nog mRNAs (Fig. 3E; see also Fig. 2A). A similar pattern of regulation was also observed for BMP4 (Supplemental Fig. S4B). These findings suggest that in the hair bulb, BMP signaling in the DP is under tight regulation by multiple positive and negative regulators.

$B M P$ regulation of $D P$ signature genes is DP-specific and not recapitulated in dermal fibroblasts or during osteogenic differentiation

Since DP cells are specialized mesenchymal cells that are related to dermal fibroblasts and since BMP signaling plays an important role in generating AP-positive osteoblasts for bone formation and mineralization (Leboy 
Figure 3. Evidence of BMP signaling in the DP in vivo and in vitro. (A) Bmp6 mRNA is specifically expressed in the DP as judged by RT-PCR of FACS-purified DP niche cell populations and skin fractions (top) and by in situ hybridization (bottom; shown is hair bulb region; lines demarcate the DP area). (HF) Back skin follicles; (Wh) whisker HFs; (Mx) matrix; (ORS) outer root sheath; (DF) dermal fraction; (Mc) melanocytes; (Der) dermis; (Epi) epidermis. (B) Real-time PCR detects Bmpr1a mRNAs in all isolated hair bulb cell fractions. $(C, D)$ Immunofluorescence of pSMAD1 of back skin hair bulb regions (C) and cultured DP cells $\pm 400 \mathrm{ng} / \mathrm{mL}$ BMP6 $(D)$. Antibodies are shown, with color-coding according to the secondary antibodies. (Blue) DAPI. $\beta_{4}$-Integrin or white lines denote demarcation between DP and follicle. KIT was used to distinguish Mc. Graph at right presents quantification of the culture data. $(E)$ Dose-dependent effects on four BMP-sensitive DP signature genes, and demonstration that

A
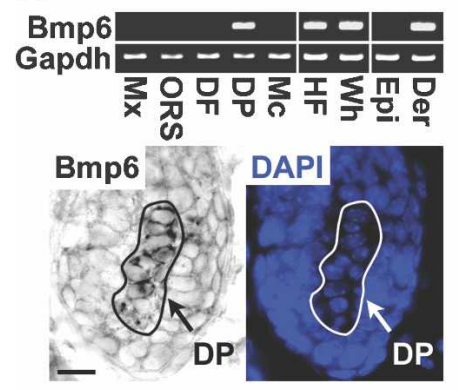

C

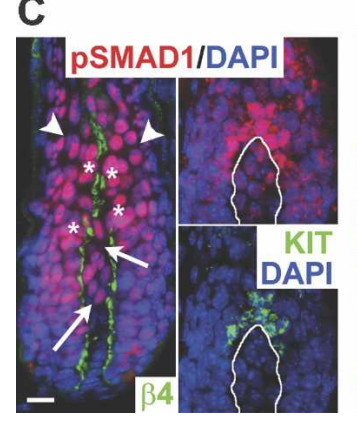

B

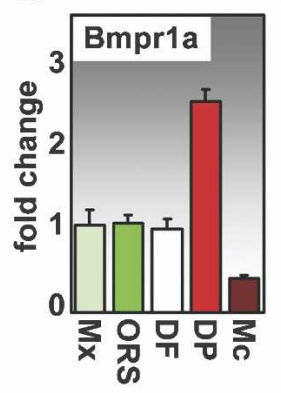

E

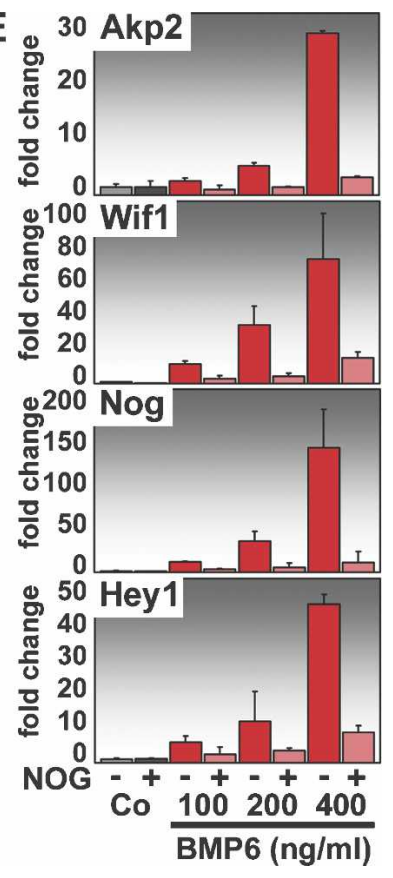
the effects can be blocked by the BMP inhibitor Noggin (NOG). FACS-sorted DP cells were cultured in medium supplemented as shown. Real-time PCR was performed and normalized relative to untreated control (Co). Error bars indicate SD of duplicate experiments.

2006), we wondered how specific BMP-mediated regulation of DP signature genes is to DP cells. To address this question, we first compared the effects of BMP6 on dermal (3T3) fibroblasts with that of freshly isolated DP cells. Of the DP signature genes tested, none was expressed comparably in untreated fibroblasts, nor did they change appreciably in response to BMP6 (Fig. 4A). This was true whether we cultured the cells in fibroblast medium $(\mathrm{F})$ or in DP medium (A, AmnioMAX).

We also contrasted our results with those obtained with C2C12 myoblast cells, known to differentiate toward the osteoblast lineage upon exposure to BMPs (Cheng et al. 2003). In C2C12 cells Nog, Hey1, and Akp2 were all up-regulated by BMP6 (Fig. 4B). In contrast, some other BMP6-sensitive DP signature genes were not induced in BMP6-treated C2C12 cultures (Fig. 4B, bottom row). Moreover, certain established osteoblast genes (Peng et al. 2003) such as Bglap (osteocalcin), Sox9, and Idb2 were induced by BMP6 only in C2C12 cells and not in DP cells (Fig. 4B, top row). These findings underscore the intrinsic features of DP cells and their distinctive response to BMPs.

\section{BMP treatment of DP cells in vitro enhances their ability to induce hair formation in vivo}

Since DP cells diminish their molecular signature in vitro, and since this effect can be ameliorated by BMP treatment, we wondered how this might have an impact on the loss of hair-inducing activity of DP cells when cultured in vitro (Kishimoto et al. 2000). To address this issue, we performed chamber-graft hair growth assays in which epidermal KC and fresh dermal cell preparations (also containing DP cells) are transferred into silicone chambers that had been placed over full-thickness wounds on the backs of Nude mice (Lichti et al. 1993; Weinberg et al. 1993). Here we modified this assay to combine GFP-expressing KC and FACSorted pure cultured DP cells that allowed monitoring the graft performance and ensured that the hair-inducing effects are derived from DP cells, respectively (Fig. 5A).

As expected, when $\mathrm{KC}$ were grafted alone, they provided a covering to the wound site but no hairs developed (Fig. 5A, left panel). In contrast, KC engraftments supplemented with cultured DP cells exhibited both reepithelialization and sparse hair formation (Fig. 5A, middle panel). Notably, when DP cells were cultured in medium containing BMP6, their capacity to induce hair was improved compared with the control DP cells (Fig. $5 \mathrm{~A}$, right panel). We qualitatively (Fig. $5 \mathrm{~B}$ ) and quantitatively (Fig. 5C) assessed this effect over a range of 10 different experiments. Even when effects of BMPs were moderate, HF production was always enhanced when DP cells were treated with BMPs (Fig. 5B). Interestingly, although DP cells usually became senescent and stopped growing between passages four and six, in one experiment, BMP-treated DP cells could be expanded until passage eight, where they still induced HF formation (data not shown). That said, while BMPs delayed, they did not completely avert the loss of hair-inducing ability, which otherwise typically occurred within the first three passages of control DP cultures.

To monitor the boundaries and origins of epidermal and DP cells, we grafted male cells onto female Nude 
A
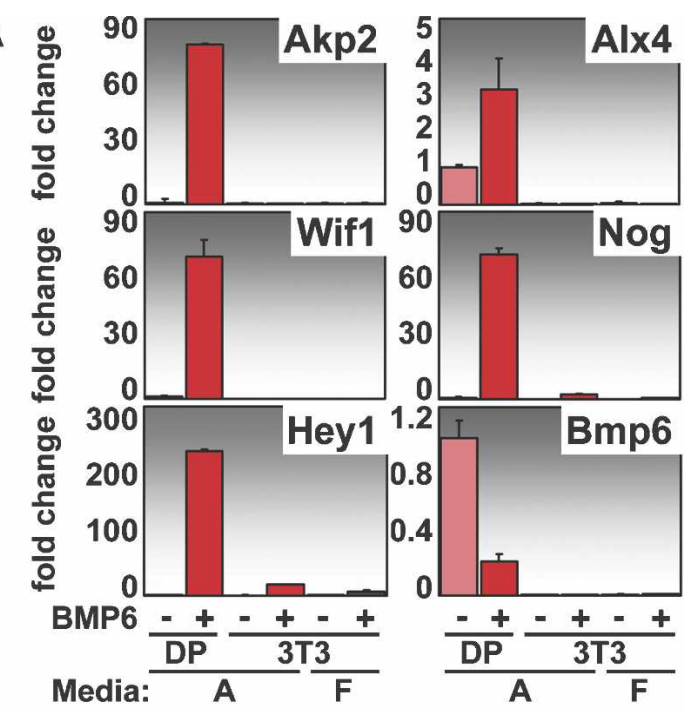

B

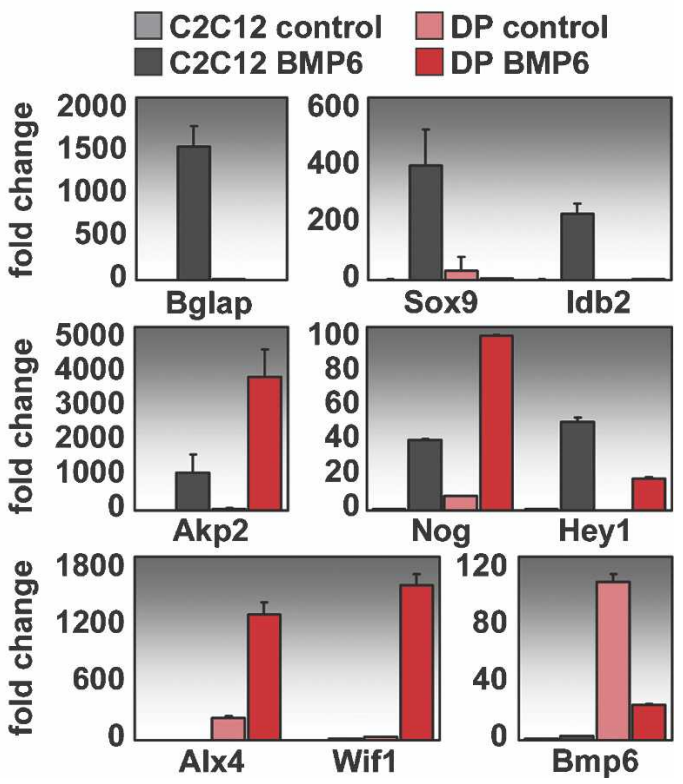

Figure 4. BMP6-mediated DP signature gene regulation is DPspecific and not recapitulated in dermal fibroblasts or differentiating osteogenic cells. (A) FACS-purified DP cells were cultured in AmnioMAX medium (A) $\pm 400 \mathrm{ng} / \mathrm{mL}$ BMP 6 for $6 \mathrm{~d}$. 3T3 dermal fibroblasts were grown in both A and F media for comparisons and were treated in parallel. Cells were harvested, and isolated mRNAs were subjected to real-time PCR. Shown are representative data for six genes. All fold changes were normalized relative to untreated DP control. Note that DP signature gene regulation by BMP6 was observed only with DP and not $3 \mathrm{~T} 3$ cells. (B) Multipotent C2C12 cells (gray), known to differentiate into osteoblasts when treated with BMPs, and DP cells (red) were cultured and tested as above for expression of known BMP-induced osteoblast genes (top and middle rows), or DP signature genes (middle and bottom rows). All fold changes were normalized relative to the untreated $\mathrm{C} 2 \mathrm{C} 12$ control sample. Error bars indicate SD of duplicate experiments.

mice, and conducted fluorescence in situ hybridization (FISH) with Y-chromosome (Ychr) probes (Fig. 5D). Underscoring probe specificity, no Ychr-positive dermal cells were detected in either host skin (shown) or KC control skin (data not shown). In contrast, grafts containing BMP6-treated DP displayed Ychr-positive cell clusters at centers of newly formed HFs (Fig. 5D). These clusters labeled with antibodies against a number of DP markers and were also positive for AP activity (Fig. 5D; additional data not shown). Thus, properties of the DP signature that were otherwise lost without BMP treatment in culture were restored when cells were exposed to their natural environment.

Interestingly, a number of AP-negative cells within dermis also scored positive for Ychr (Fig. 5D, arrows). These cells appeared to be fibroblasts, suggesting that DP cells can contribute to other dermal cells in a wound setting. Recently, similar behavior was shown for dermal sheath cells that normally line the ORS but that contribute to dermal regeneration upon skin injury (Gharzi et al. 2003). Together, these findings suggest that under the conditions used here, BMP6-treated DP cultures not only improved HF-inducing capabilities, but also adopted at least one alternative lineage.

\section{$B M P$ signaling is required for $H F$ induction by $D P$ cells}

The data thus far indicated that BMP signaling favorably regulated DP signature genes in vitro and improved HF induction in vivo. While BMP signaling did not appear to be sufficient on its own to fully maintain $\mathrm{DP}^{\prime}$ s ability to induce HF formation, we wondered whether it nevertheless might be an indispensable component of the process. To address this question, BMP signaling had to be specifically abolished in the DP. This is presently not possible by conventional mouse genetics, since no known promoter uniquely targets expression to DP. To circumvent this caveat, we devised the in vitro/in vivo hybrid knockout strategy outlined in Figure 6A. We first crossed the Bmpr1a floxed mouse strain $\left(B m p r 1 a^{f 1 / f 1}\right)$, targeted for conditional loss of the BMP receptor (Mishina et al. 2002), with Rosa-Cre $e^{\text {ERtam }}$ mice, encoding a tamoxifeninducible Cre recombinase under the control of the ubiquitously active Rosa26 promoter (Badea et al. 2003). To isolate pure populations of DP cells, we then bred these mice with our K14-H2B-GFP/Lef-RFP reporter mice and employed FACSorting (Rendl et al. 2005). We then activated Cre-mediated Bmpr1a gene ablation by hydroxytamoxifen (OHT) treatment of pure DP cells in vitro and tested their inducing activity in the chambergraft hair growth assay described above (Fig. 6A). In this case, to specifically track the fate of DP cells, we isolated male DP cells, combined them with female GFP-positive $\mathrm{KC}$, and engrafted them onto female Nude mice.

Real-time PCR with primers specific for the ablated exon 2 confirmed that after $3 \mathrm{~d}$ of OHT treatment in vitro, wild-type Bmpr1a expression was abolished (Fig. 6B). Prior to grafting, DP cells were expanded for 7-12 d (one passage), and during this time, no obvious morphological and growth differences were observed (Fig. 6C). Additionally, as judged by annexin $\mathrm{V}$ staining and by 
propidium iodide uptake, the spontaneous apoptosis rates of Bmpr1a-null DP and control cells were comparable (Fig. 6D).

While Bmpr1a ablation did not alter DP growth or morphology, it had a marked effect on expression of DP signature genes sensitive to BMPs. Under early culture conditions, when expression of BMP-sensitive signature genes could still be detected, Akp2, Wif1, and other signature mRNA levels were diminished compared with control cultures (Fig. 6E). Interestingly, only Bmp6 was up-regulated, again highlighting the circuitry of the integrated negative feedback loop that we uncovered earlier. Overall, the effects appeared to be specific for the BMP signaling pathway, as genes that had scored previously as not responsive to BMP treatment similarly showed no effect on Bmpr1a ablation.

Loss of BMP receptor activity also compromised the ability of DP cells to induce HFs in full-thickness chamber-graft assays in vivo, where GFP-positive KC were combined with cultured DP cells as the only source of dermal cells. Thus, while mock-treated Bmpr1 $a^{\text {flfl }} /$ RosaCre ${ }^{\text {ERtam }}$ DP control cells generated robust hair growth, OHT-treated Bmpr1a $a^{f l f l} /$ Rosa-Cre $e^{\text {ERtam }}$ DP cells showed little or no ability to induce hair formation (Fig. 7A). $\mathrm{OHT}$ on its own had no effect on hair-forming activity, indicating that the effects were specific for loss of BMP signaling in the DP (data not shown).

The degree of GFP epifluorescence on the graft surface varied somewhat with different experiments, but it was generally comparable between control and knockout grafts (Fig. 7A, right panels; Supplemental Fig. S6A). In addition, OHT-treated, Bmpr1a-targeted DP cells showed some variability in the degree to which they impaired hair growth, ranging from complete absence of externally visible hair (Fig. 7A) to a few hairlike protrusions (Supplemental Fig. S6A). Overall, effects were substantial.

Figure 5. BMP6 treatment of DP cultures enhances their inductive ability in vivo. (A) K14-GFPactin-expressing KC prepared from newborn male back skins were grafted onto back skins of female Nude mice alone (left panel) or in the presence of FACS-purified male DP cells (passage 1) that were cultured $\pm 400 \mathrm{ng} / \mathrm{mL}$ BMP6 (middle and right panel). After 3-4 wk, grafts were photographed in bright-field or GFP epifluorescence. $(B)$ Summary of hair growth in 10 independent experiments. The amount of hair growth was classified as follows: no growth $(-)$; few hairs formed $(<50)(+)$; medium hair growth $(50$ 150) $(++)$; full dense hair growth $(>150)(+++)$. Each line represents an individual experiment. Note that control DP cells usually entered senescence in the fourth through sixth passages. $(C)$ Quantification of area of hair growth. The graft area that was covered by hair growth was measured and expressed as percentage of the total graft area as determined by GFP expression. (D) Skin sections from grafts of KC + BMP6-treated DP cells. (Top) The host/graft boundary was identified by fluorescence microscopy. AP activity (red) marks the DP cells. Bar, $100 \mu \mathrm{m}$. (Bottom) FISH with a Y-chromosome probe (Y-chr) identifies the engrafted cells. Note that neither the male dermal fibroblasts (arrowheads) nor the male DP cells (arrows) were seen when male KCs were grafted alone (not shown). Bars, $25 \mu \mathrm{m}$.
Histological analyses revealed abundant well-formed HFs in skins with grafted control DP cells (Fig. 7B, "Mock"), but large areas of either completely absent or aberrant downgrowths with DP knockout cells (Fig. 7B, "OHT," arrowheads). For fair comparison, the amount of grafted area in these sections was judged by the integration of nuclear GFP-positive KCs, which was similar in control and knockout samples (Fig. 7C). Importantly, the paucity of HFs in these engraftments did not appear to be attributable to a failure of Bmpr1a-null DP cells to grow in vivo, since underlying dermis generated in the graft displayed Ychr-positive cells (Fig. 7D ["OHT," arrowheads], E [panels ii,iii]; Supplemental Fig. S6B). However, control DP cells additionally gave rise to HFs, each en-

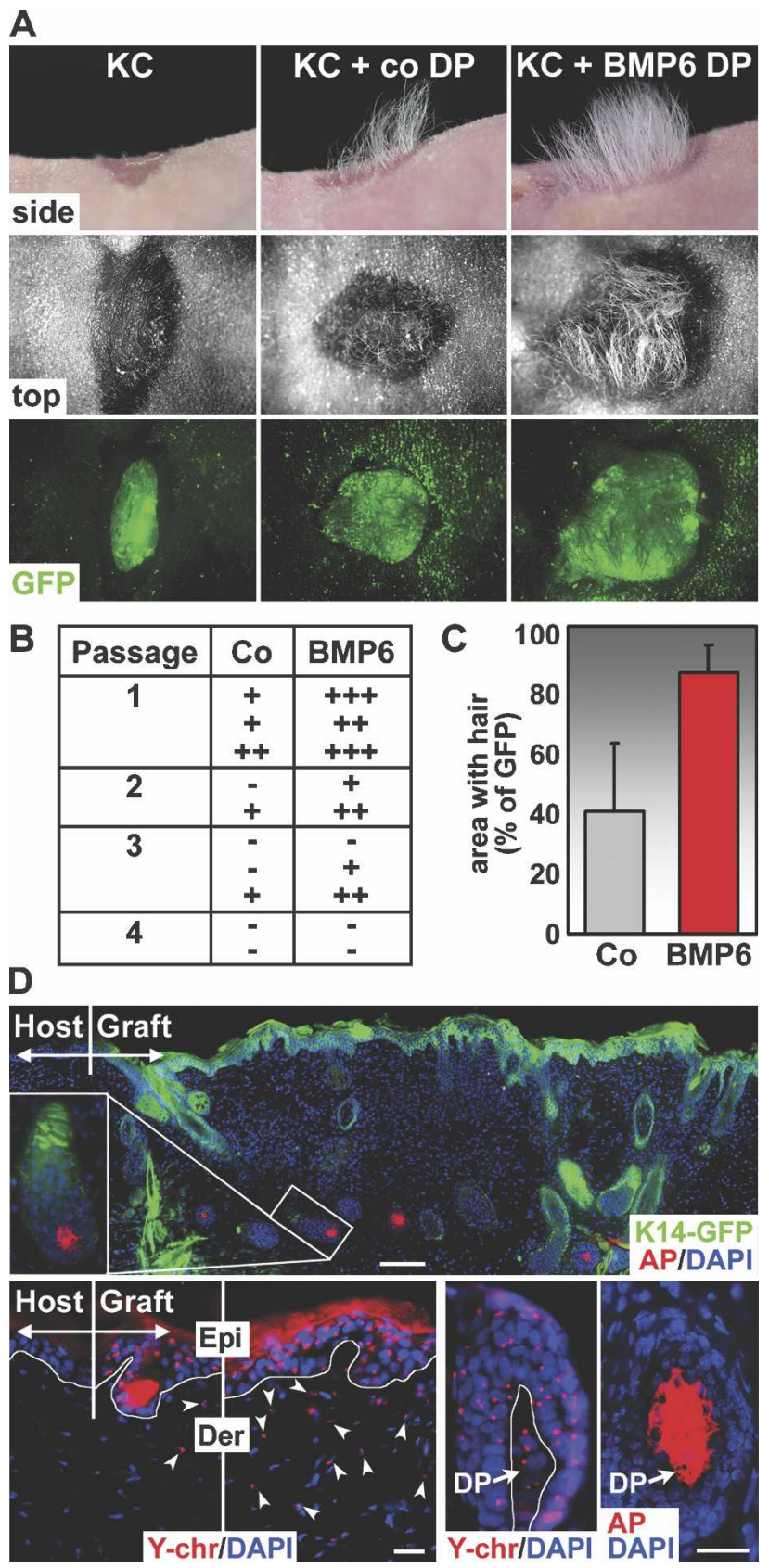


casing a pocket of Ychr-positive DP (Fig. 7D [arrows, "Mock"], E [panel i]) and surrounded by a Ychr-positive dermal sheath. In contrast, the few HF-like downgrowths generated from Bmpr1a-null DP cells lacked signs of an organized DP (Fig. 7D ["OHT"], E, [panel ii]). A summary of the outcome of DP-specific ablation of Bmpr1a in eight experiments is presented in Figure 7F. When we quantified the hair growth area within the GFP-positive graft, a robust reduction of $87 \%$ was observed compared with control (Fig. 7G).

Finally, we addressed whether the DP signature changes in vivo when BMP signaling is compromised. Unexpectedly, the Ychr-positive dermal cells in the Bmpr1a-targeted DP grafts displayed residual AP activity (Fig. 8A, "OHT," arrowheads). The strongest AP activity

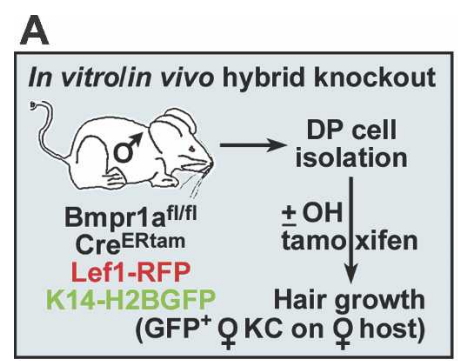

B

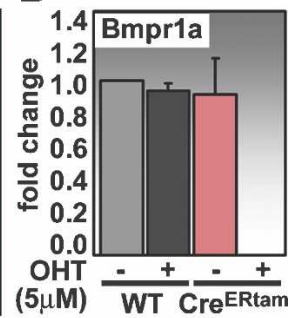

C
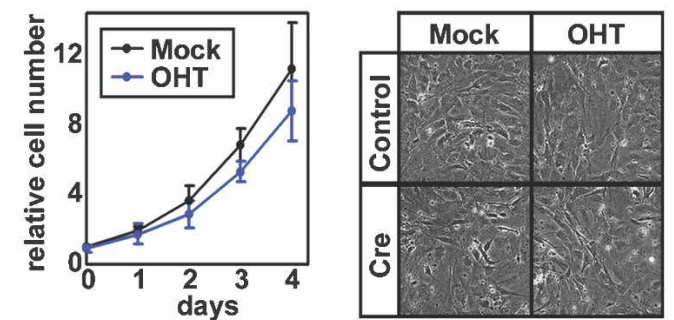

\section{D}
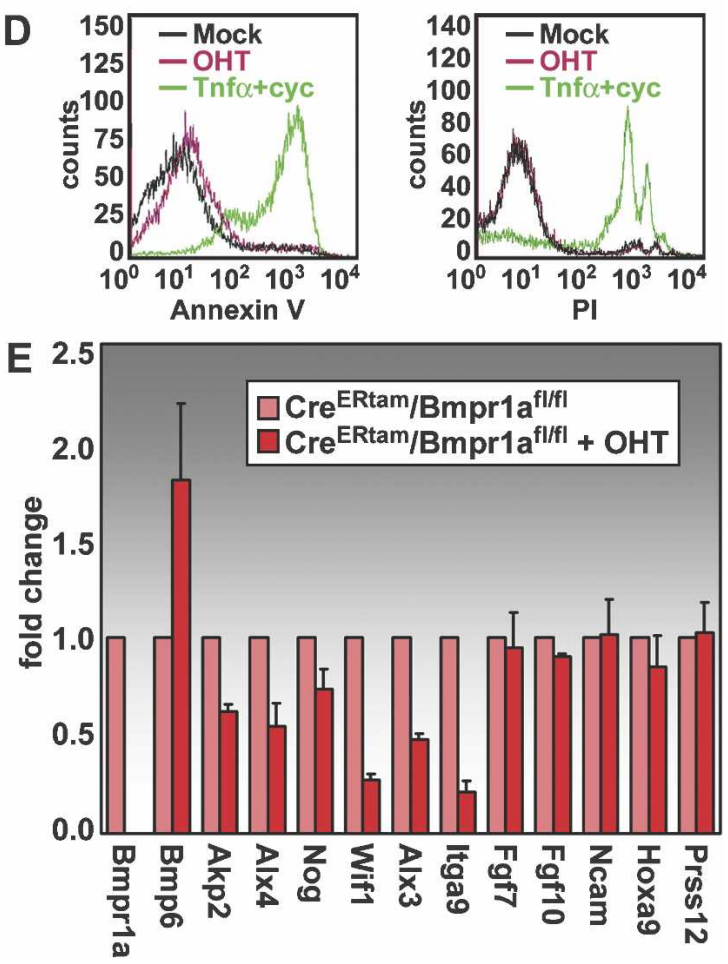

was found at the base of aberrant HF-like downgrowths (Fig. 8C, arrow in panel ii) at levels similar to control DPs (Fig. 8A ["Mock," arrows], C [panel i]). However, knockout cells that integrated into the dermis also exhibited aberrant, low-level AP activity (Fig. 8C, arrowheads in panels ii,iii). pSMAD1 staining confirmed the absence of BMP signaling within dermal cells. In addition, BMP signaling was compromised within the few HF-like epithelial downgrowths (Fig. 8D). Interestingly, in contrast to AP, WIF1 and NCAM were not detected in the dermal fibroblasts but were found to varying extents in dermal cells surrounding aberrant HF downgrowths (Fig. 8B,C,G; Supplemental Fig. S6C,F). Since DP signature proteins such as NCAM and WIF1 are not expressed by normal dermal sheath, we surmise that these positive cells reflected a failure of the Bmpr1a-null cells to organize into a proper DP structure and stimulate HF formation. Finally, HOXA9 and HHIP, which are exclusively expressed in normal DP (Fig. 8E,F, "Mock"), were not detected in dermal cells within knockout grafts (Fig. 8E,F, "OHT"; Supplemental Fig. S6D,G). Together, these data suggest that the ability of DP cells to respond to BMPs is required for them to orchestrate the appropriate microenvironment to establish proper DP signature and function.

\section{Discussion \\ DP cell fate specification: the impact of the microenvironment on DP character}

The goal of our study was to exploit our recent genomic characterization of the molecular identity of the DP and its surrounding niche neighbors and systematically dissect the special features of hair bulb microenvironment that enable DP cells to exert their inductive powers. By analyzing how the molecular signature changes when DP cells are removed from their niche and placed in culture, we were able to identify not only a subset of genes whose expression is intrinsic to DP, but also another gene set whose expression is lost upon culture. The loss

Figure 6. DP-specific targeting of the Bmpr1a gene and effects on DP cells in vitro. (A) Schematic of DP-specific knockout strategy. FACS-purified male DP cells from K14-H2B-GFP/Lef1RFP/Rosa-Cre $e^{E R t a m} / B m p r 1 a^{f l f l}$ mice were treated with OHT to activate Cre-mediated gene ablation in vitro and were grafted together with female K14-H2B-GFP KC onto female Nude mice in in vivo hair growth chamber-graft assays. $(B)$ Real-time PCR verification of quantitative Bmpr1a exon 2 ablation within $3 \mathrm{~d}$ after culture initiation and OHT treatment. $(C, D)$ Normal proliferation, morphology, and apoptosis levels after Bmpr1a ablation in pure DP cells. Apoptosis assays were performed by Annexin $\mathrm{V}$ and propidium iodide (PI) stainings followed by FACS. TNF $\alpha$ treatments were conducted as positive controls. $(E)$ Realtime PCR analysis of DP signature genes upon Bmpr $1 a$ ablation. RNAs were isolated just prior to chamber grafting (see Fig. 7); i.e., after $7-12 \mathrm{~d}$ at passage 1 , when DP signature genes are still expressed. Note the selective effects on expression of BMP6sensitive DP signature genes in Bmpr1a-deficient DP cultures. Bars are the means of three independent experiments. 

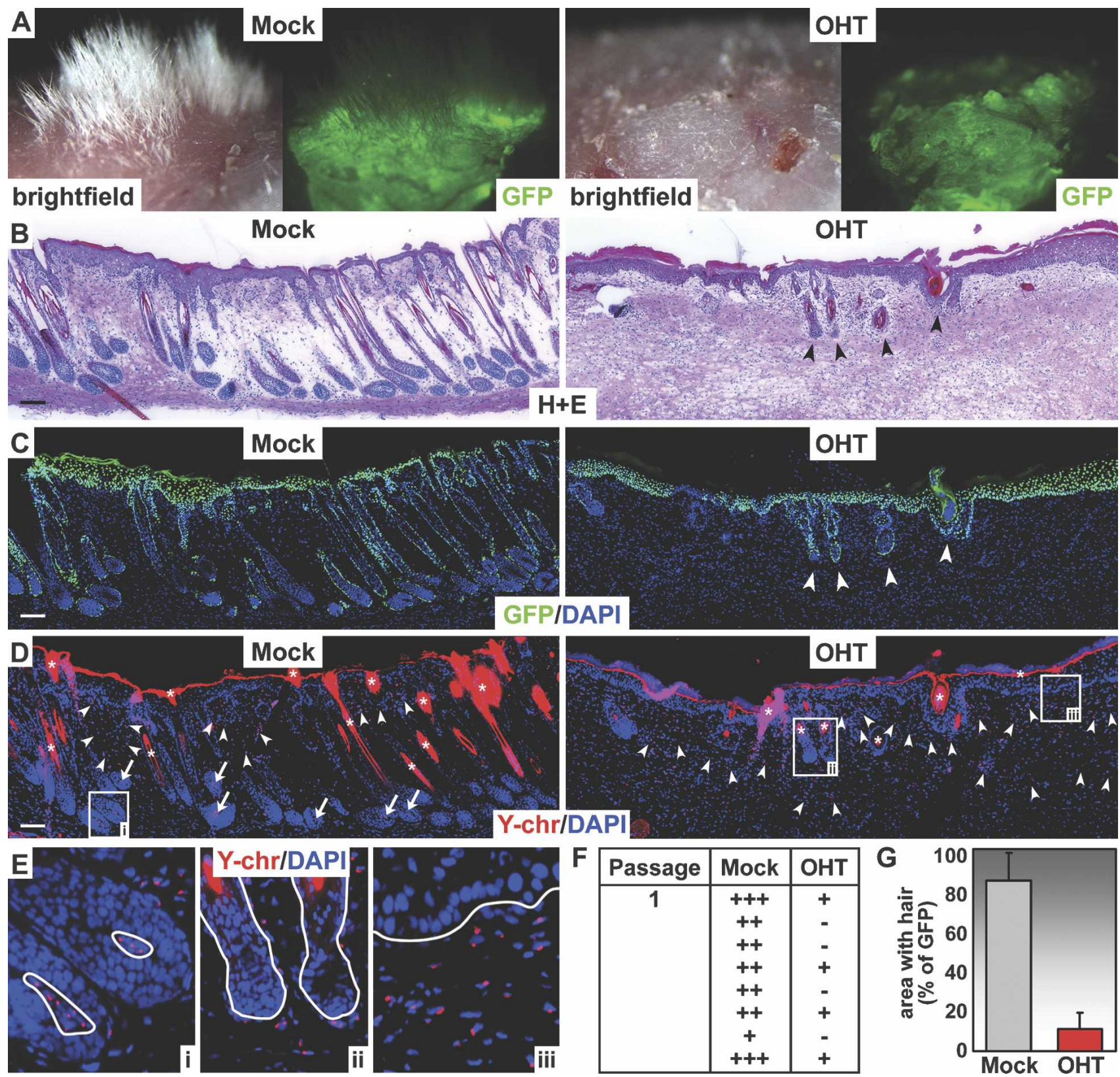

\begin{tabular}{|c|c|c|}
\hline Passage & Mock & OHT \\
\hline 1 & +++ & + \\
& ++ & - \\
& ++ & - \\
& ++ & + \\
& ++ & - \\
& ++ & + \\
& + & - \\
& +++ & + \\
\hline
\end{tabular}

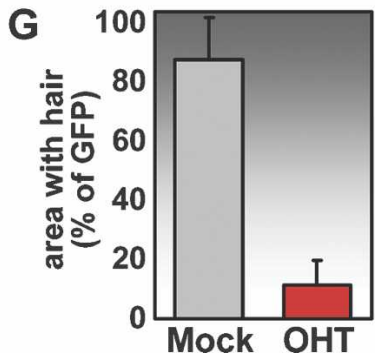

Figure 7. DP-specific ablation of Bmpr1a diminishes their hair induction capacity. DP cells from male Bmpr1a knockout (OHT) and control (Mock) mice were grafted together with female K14-H2B-GFP KC onto the backs of female Nude mice. (A) Side view of the graft area after $3 \mathrm{wk}$. Shown is a representative example of four separate experiments. (Right frames) GFP epifluorescence served as control for comparable graft performance. $(B, C)$ Serial sections of grafts stained with hematoxylin/eosin $(\mathrm{H}+\mathrm{E})(B)$ and examined by GFP fluorescence to ensure fair comparisons of graft samples $(C)$. Arrowheads denote aberrant follicle-like downgrowths in grafts containing Bmpr1a-null DP cells. ( $D, E)$ Y-chromosome (Y-chr) FISH (red). DAPI counterstaining in blue. Frames in $E$ are magnified images of boxed areas from $D$ to show integration of both wild-type and Bmpr1a-null DP-derived male cells within the dermis of the grafts. Note that wild-type but not Bmpr1a-null DP cultures generated HFs with DP (arrows) and dermal sheaths. Note presence of additional DP-derived male cells within the dermis (arrowheads). Asterisks denote autofluorescence within the cornified layer of the epidermis and the hair shafts. White lines highlight the BM around the DP (Mock) and at the epidermal/dermal border (OHT). Bars, $100 \mu \mathrm{m}$. $(F)$ Summary of hair growth in eight experiments. The amount of hair growth was classified as follows: no growth $(-)$; few hairs formed $(<50)(+)$; medium hair growth $(50-150)(++)$; full dense hair growth $(>150)(+++)$. Each line represents an individual experiment. $(G)$ Quantification of area of hair growth. The graft area that was covered by hair growth was measured and is expressed as percentage of the total graft area as determined by GFP expression. 

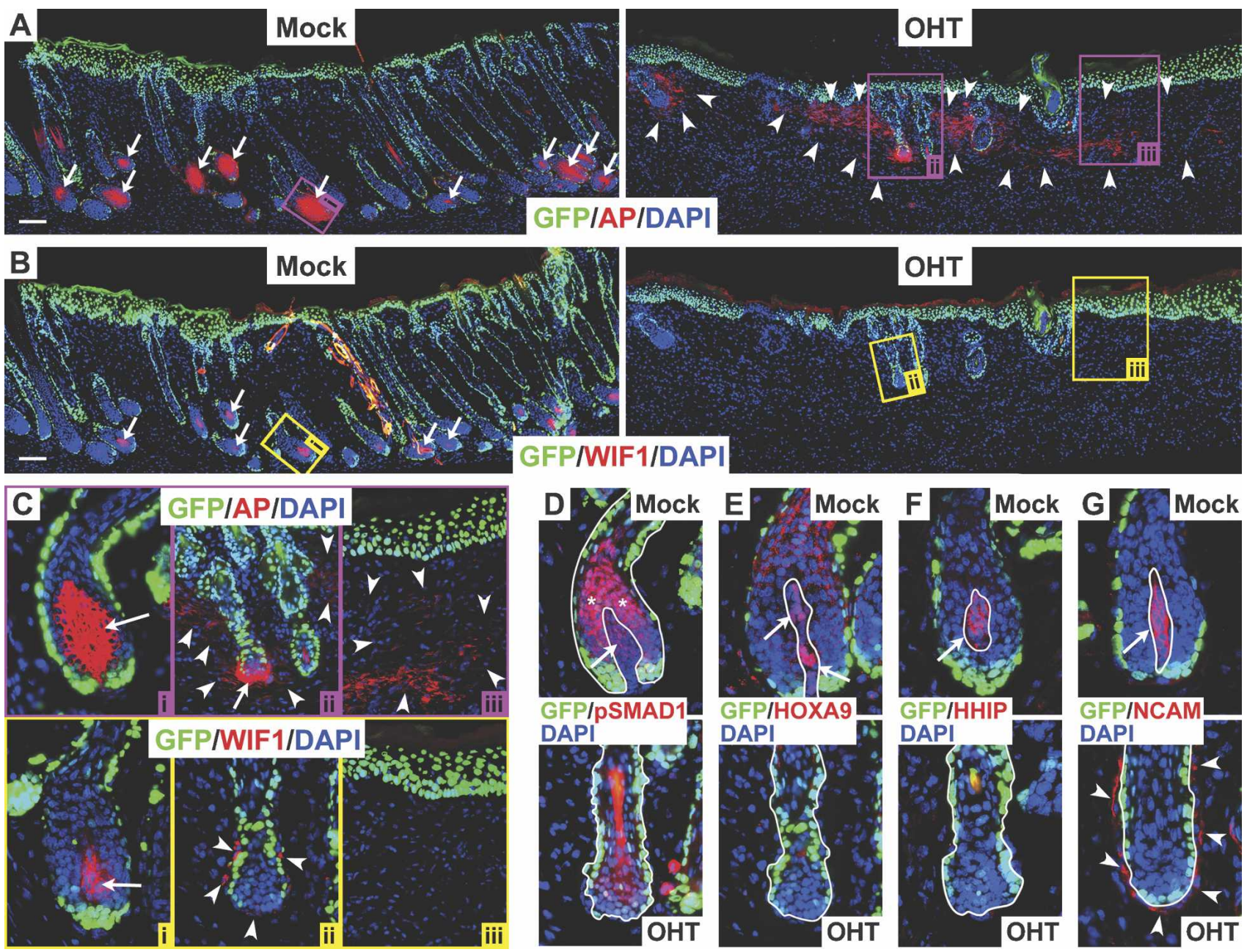

Figure 8. In vivo alterations of DP signature gene expression in grafted dermal cells derived from $B m p r 1 a$-null DP cells. $(A, B)$ Serial sections of grafts were stained for AP activity $(A)$ or WIF1 $(B)$ and subjected to fluorescence microscopy. Boxed areas (labeled i-iii) were magnified and are shown in $C$. Arrows point to expected sites of expression, while arrowheads indicate erroneous expression. $(D)$ pSMAD1 immunofluorescence of serial sections of grafts. Shown are HFs corresponding to the ones in panels $i$ and ii in $C$. Note that aberrant AP/WIF1-positive cells were pSMAD1-deficient. $(E-G)$ Immunofluorescence of graft sections stained for DP markers HOXA9, HHIP, and NCAM. Note aberrant NCAM in dermal cells lining the follicle-like downgrowths. Bars, $100 \mu \mathrm{m}$.

occurred concomitantly with a reduced ability of DP cells to promote HF morphogenesis in skin engraftments, suggesting that signature maintenance is functionally important.

In systematically screening niche factors for their ability to maintain the DP signature in vitro, we discovered that BMPs had strong positive effects that could be counteracted by BMP inhibitors. When put to a functional test, the improved molecular signature gained by BMP treatment coincided with improved hair growth in Nude mice in vivo. While this improvement did not prevent cultured DP cells from eventually losing the hair-inducing activity, the partial benefit of BMP signaling correlated with a partial restoration of the DP signature.

Our findings lend strong support to the view that a combinatorial effect will likely be necessary to fully unleash the inductive powers of cultured DPs, as initially proposed by Shimizu and Morgan (2004) in their studies on Wnt signaling. With our recent acquisition of a molecular signature for the DP and its niche, we unveiled an additional requirement for a concerted activation of multiple pathways in maintaining $\mathrm{DP}^{\prime}$ s molecular features. Many of the prominent DP signature genes that were sensitive to BMP signaling were distinct from those sensitive to Wnt pathway activation by either WNT3A treatment or Wnt3a expression. In the future it will be important to systematically dissect which DP signature genes are regulated through DP receptor-mediated interactions with Wnts, Shh, Fgfs, and other extracellular factors expressed by cells within the DP niche.

Another critical issue is how BMP signaling is regulated in vivo. In this regard, the effects of BMPs and BMP inhibitors on the DP signature in vitro were intriguing, and given that a plethora of BMPs and inhibitors are simultaneously expressed within the microenvironment of the hair bulb (Supplemental Fig. S5), it is tempting to 
speculate that it must be the overall balance of positive and negative BMP signaling molecules that determines the outcome and orchestrates the DP identity within this niche. In the bulb, this balance appeared to be tipped toward active BMP signaling in vivo, since we detected pSMAD1-positive DP nuclei.

The presence of multiple positive and negative regulators also suggests built-in redundancy, which is exemplified not only by the similar effects of various hair bulb BMPs on the DP signature but also by mice targeted for BMP genes encoding BMP6 (Solloway et al. 1998), BMP7 (Dudley et al. 1995), and BMP8a (Zhao et al. 1998), all of which are expressed in the hair bulb but none of which exhibit an apparent hair phenotype when ablated. In light of our studies, we examined skin sections of mice deficient for BMP6 since it had the most potent effects. We confirmed that Bmp6-null mice displayed normal HFs and also showed that BMP-regulated DP signature genes are still expressed (Supplemental Fig. S7A,B).

When placed within the framework of previously reported roles for BMP signaling in restricting proliferation of epidermal cells (Blessing et al. 1996) and HF cells, including bulge stem cells and matrix cells (Kulessa et al. 2000; Kobielak et al. 2003, 2007; Andl et al. 2004; Blanpain et al. 2004; Ming Kwan et al. 2004; Yuhki et al. 2004; for review, see Botchkarev 2003), our findings provide an important new role for BMP signaling in maintaining features of DP cells that are instrumental for HF formation. The regulatory feedback circuits governing Bmp6 and Noggin gene expression in DP cells and the directionality of BMP signaling in the niche provide further insights into the complexities of this mesenchymal-epithelial cross-talk. While further studies will be needed to fully understand this process, the apparent gradient of pSMAD1 in the nuclei of DP and its neighbors may be a reflection of this circuitry in action.

\section{In vivo relevance: a novel DP-specific gene targeting approach}

With the ability to purify DP niche cells (Rendl et al. 2005), the BMP-mediated effects on DP signature genes in culture and enhanced hair formation upon grafting could be directly attributed to DP cells. Moreover, our Rosa26-Cre $e^{E R t a m} / B m p r 1 a^{f l / f 1}$-inducible gene knockout experiments illustrate how this purification scheme can be applied to mice of different genetic backgrounds to circumvent the current lack of DP-specific gene targeting tools and still conduct DP-specific loss-of-function studies. Although a genetic loss-of-function study such as the one we described here is superior, this strategy could be applied to pure populations of wild-type DP cells infected with lentiviral vectors expressing either shRNAs for knockdowns or transgenes for gain-of-function analyses. Such approaches could expedite the speed at which we and others will be able to test the physiological relevance of DP signature genes. Ultimately, it will be important to manipulate DP signature genes using DP-specific Cre lines in a normal developmental context.
Another advantage of our in vitro/in vivo hybrid knockout method is the ability to use female GFP-tagged $\mathrm{KC}$ and purified male DP cells to conduct grafting experiments on female Nude mice. This enabled us to track the fates of our engrafted Bmpr1a-null DP cells and establish an essential role for BMP signaling in DP-induced hair formation. Moreover, it suggested that in the absence of Bmpr1a, DP cells can still survive and proliferate in skin, but they cannot maintain their proper identity or their proper fate.

In the few cases in our knockout graft experiments where HF-like downgrowths did occur, they did not harbor a proper DP or a regularly layered architecture of epithelial cells, although at times they were accompanied by hair shaftlike protrusions. Since most graft regions were devoid of these rudimentary, aberrant formations, we surmise that they arose from the residual instructive ability of a few DP cells that may have been delayed in targeting both Bmpr1a alleles. Alternatively, these structures may reflect that even without BMP signaling, DP cells retain certain features of their signature, and this could be sufficient to induce aberrant mesenchymal-epithelial cross-talk.

\section{Summary}

In closing, we systematically screened growth factors from the DP niche microenvironment for the ability to regulate the molecular identity and hair-inducing qualities of DP cells. We identified BMP signaling as a determinant of stem cell-activating, hair-inducing cell fate. Finally, we showed that BMP signaling is not sufficient on its own to maintain the DP signature or DP's HFinductive properties. The novel assay we devised to conduct gain- and loss-of-function studies specifically in DP cells opens the door to future studies in dissecting the complex repertoire of epithelial-mesenchymal growth factor and receptor signaling that takes place in the DP niche.

\section{Materials and methods}

Mice

DP cells were isolated from K14-H2B-GFP/Lef-RFP reporter mice by FACSorting as described previously (Rendl et al. 2005). For Bmprla ablation in DP cells, the reporter mice were crossed with Bmpr1a $a^{f l f 1}$ (Mishina et al. 2002) and Rosa-Cre $e^{\text {ERtam mice }}$ (Badea et al. 2003) (available at the Jackson Laboratory, stock no. 004847). For chamber grafts, immunocompromised Nude mice were obtained from Charles River Laboratories $(\mathrm{Nu} / \mathrm{nu})$ or Taconic (Swiss nude). Bmp6 knockout pups were kindly provided by the Robertson laboratory (Solloway et al. 1998).

\section{Cell culture}

FACS-isolated DP cells were cultured in AmnioMAX C-100 medium (Bratka-Robia et al. 2002). Growth factor, growth curve, and apoptosis experiments were performed at passage 1. For growth factor experiments, cells were cultured for 3-6 d and harvested for RT-PCR, AP activity, and immunofluorescence. 
A list of the growth factors and concentrations is provided in the Supplemental Material. For proliferation analysis $50 \mu \mathrm{M} \mathrm{BrdU}$ (Sigma) was administered. For induction of apoptosis, $100 \mathrm{nM}$ $\mathrm{TNF} \alpha(\mathrm{R} \& \mathrm{D}$ Systems)/100 ng/mL cycloheximide (Sigma) was applied. Cre-mediated gene ablation was induced with $5 \mathrm{nM}$ OHT (Sigma). Early passage 3T3-J2 dermal fibroblasts and $\mathrm{C} 2 \mathrm{C} 12$ cells (a kind gift from the Greengard laboratory) were cultured in F medium (DMEM/10\% FBS). For growth curve analyses, BMP6 and OHT-treated DP cells were plated at late passage 1 at low density (5000 cells per square centimeter), trypsinized, and counted in triplicate with a Coulter Counter (Beckman). For retroviral overexpression of a constitutively active form of Bmpr1a (ALK3-QD, kind gift from K. Miyazono) (Akiyama et al. 1997) or Bmp6 and Wnt3a (PCR-cloned from cDNA), sequences were subcloned into the MSCV-IRES-GFP retroviral vector (kindly provided by W. Pear, University of Pennsylvania, Philadelphia). Retroviral supernatants were produced in phoenix cells, and DP cells were infected following standard procedures.

\section{Chamber-graft assay}

Chamber grafts were performed as described (Lichti et al. 1993; Kishimoto et al. 2000; Blanpain et al. 2004). Experiments included a positive control of cell suspensions from freshly isolated wild-type dermis plus K14-GFPactin (Vaezi et al. 2002) or K14-H2B-GFP KC and a negative control of KC alone. Shortterm cultured (4-7 d in KSFM; Invitrogen) newborn KC $\left(2 \times 10^{6}\right)$ and BMP6 (400 ng/mL; R\&D System) or control-treated DP cells $\left(4 \times 10^{6}\right)$ in the first through fouth passages were used for maintenance grafts. For knockout experiments, DP cells were grafted after expansion in the first passage $(\sim 9-12 \mathrm{~d}$ after sorting and plating $\sim 2 \times 10^{6}$ cells). Hair typically appeared after 17-24 d.

See the Supplemental Material for additional experimental details.

\section{Acknowledgments}

We thank Y. Mishina (National Institutes of Health) for floxed Bmpr1a mice, E. Robertson for Bmp6 knockout mice, and all other colleagues who provided us with special antibodies, cells, and reagents, whose gifts are cited in the text. We are thankful to Svetlana Mazel, Olga Malkova, and Xiaoxuan Fan (FCRC Facility) for FACSorting DP cells; to Soosan Ghazizadeh (Stony Brook) and Nicole Stokes (Fuchs laboratory) for their technical expertise and assistance with chamber grafting experiments; and to Geraldine Guasch, Valerie Horsley, Hoang Nguyen, Jonathan Nowak, and all other present and former members of the Fuchs laboratory for their valuable discussions and advice. M.R. is a fellow of the Max Kade Foundation and a recipient of an Erwin-Schrodinger Fellowship from the Austrian Science Fund. E.F. is an investigator of the Howard Hughes Medical Institute. This work was supported in part by Starr funds from the Tri-Institutional Stem Cell Initiative.

\section{References}

Akiyama, S., Katagiri, T., Namiki, M., Yamaji, N., Yamamoto, N., Miyama, K., Shibuya, H., Ueno, N., Wozney, J.M., and Suda, T. 1997. Constitutively active BMP type I receptors transduce BMP-2 signals without the ligand in C2C12 myoblasts. Exp. Cell Res. 235: 362-369.
Alonso, L. and Fuchs, E. 2006. The hair cycle. J. Cell Sci. 119: 391-393.

Andl, T., Ahn, K., Kairo, A., Chu, E.Y., Wine-Lee, L., Reddy, S.T., Croft, N.J., Cebra-Thomas, J.A., Metzger, D., Chambon, P., et al. 2004. Epithelial Bmprla regulates differentiation and proliferation in postnatal hair follicles and is essential for tooth development. Development 131: 2257-2268.

Badea, T.C., Wang, Y., and Nathans, J. 2003. A noninvasive genetic/pharmacologic strategy for visualizing cell morphology and clonal relationships in the mouse. J. Neurosci. 23: 2314-2322.

Blanpain, C., Lowry, W.E., Geoghegan, A., Polak, L., and Fuchs, E. 2004. Self-renewal, multipotency, and the existence of two cell populations within an epithelial stem cell niche. Cell 118: 635-648.

Blanpain, C., Horsley, V., and Fuchs, E. 2007. Epithelial stem cells: Turning over new leaves. Cell 128: 445-458.

Blessing, M., Schirmacher, P., and Kaiser, S. 1996. Overexpression of bone morphogenetic protein-6 (BMP-6) in the epidermis of transgenic mice: Inhibition or stimulation of proliferation depending on the pattern of transgene expression and formation of psoriatic lesions. J. Cell Biol. 135: 227-239.

Botchkarev, V.A. 2003. Bone morphogenetic proteins and their antagonists in skin and hair follicle biology. J. Invest. Dermatol. 120: $36-47$.

Botchkarev, V.A. and Sharov, A.A. 2004. BMP signaling in the control of skin development and hair follicle growth. Differentiation 72: 512-526.

Bratka-Robia, C.B., Mitteregger, G., Aichinger, A., Egerbacher, M., Helmreich, M., and Bamberg, E. 2002. Primary cell culture and morphological characterization of canine dermal papilla cells and dermal fibroblasts. Vet. Dermatol. 13: 1-6.

Calvi, L.M., Adams, G.B., Weibrecht, K.W., Weber, J.M., Olson, D.P., Knight, M.C., Martin, R.P., Schipani, E., Divieti, P., Bringhurst, F.R., et al. 2003. Osteoblastic cells regulate the haematopoietic stem cell niche. Nature 425: 841-846.

Cheng, H., Jiang, W., Phillips, F.M., Haydon, R.C., Peng, Y., Zhou, L., Luu, H.H., An, N., Breyer, B., Vanichakarn, P., et al. 2003. Osteogenic activity of the fourteen types of human bone morphogenetic proteins (BMPs). J. Bone Joint Surg. Am. 85: 1544-1552.

Cotsarelis, G. 2006. Epithelial stem cells: A folliculocentric view. J. Invest. Dermatol. 126: 1459-1468.

Cotsarelis, G., Sun, T.T., and Lavker, R.M. 1990. Label-retaining cells reside in the bulge area of pilosebaceous unit: Implications for follicular stem cells, hair cycle, and skin carcinogenesis. Cell 61: 1329-1337.

Dudley, A.T, Lyons, K.M., and Robertson, E.J. 1995. A requirement for bone morphogenetic protein-7 during development of the mammalian kidney and eye. Genes \& Dev. 9: 27952807.

Fuchs, E. 2007. Scratching the surface of skin development. Nature 445: 834-842.

Gharzi, A., Reynolds, A.J., and Jahoda, C.A. 2003. Plasticity of hair follicle dermal cells in wound healing and induction. Exp. Dermatol. 12: 126-136.

Grose, R., Fantl, V., Werner, S., Chioni, A.M., Jarosz, M., Rudling, R., Cross, B., Hart, I.R., and Dickson, C. 2007. The role of fibroblast growth factor receptor $2 \mathrm{~b}$ in skin homeostasis and cancer development. EMBO J. 26: 1268-1278.

Guo, L., Degenstein, L., and Fuchs, E. 1996. Keratinocyte growth factor is required for hair development but not for wound healing. Genes \& Dev. 10: 165-175.

Handjiski, B.K., Eichmüller, S., Hofmann, U., Czarnetzki, B.M., and Paus, R. 1994. Alkaline phosphatase activity and localization during the murine hair cycle. Br. J. Dermatol. 131: 
303-310

Hardy, M.H. 1992. The secret life of the hair follicle. Trends Genet. 8: 55-61.

Howe, L.R., Watanabe, O., Leonard, J., and Brown, A.M. 2003. Twist is up-regulated in response to Wntl and inhibits mouse mammary cell differentiation. Cancer Res. 63: 19061913.

Jahoda, C.A., Horne, K.A., and Oliver, R.F. 1984. Induction of hair growth by implantation of cultured dermal papilla cells. Nature 311: 560-562.

Katayama, Y., Battista, M., Kao, W.M., Hidalgo, A., Peired, A.J., Thomas, S.A., and Frenette, P.S. 2006. Signals from the sympathetic nervous system regulate hematopoietic stem cell egress from bone marrow. Cell 124: 407-421.

Kishimoto, J., Ehama, R., Wu, L., Jiang, S., Jiang, N., and Burgeson, R.E. 1999. Selective activation of the versican promoter by epithelial-mesenchymal interactions during hair follicle development. Proc. Natl. Acad. Sci. 96: 7336-7341.

Kishimoto, J., Burgeson, R.E., and Morgan, B.A. 2000. Wnt signaling maintains the hair-inducing activity of the dermal papilla. Genes \& Dev. 14: 1181-1185.

Kobielak, K., Pasolli, H.A., Alonso, L., Polak, L., and Fuchs, E. 2003. Defining BMP functions in the hair follicle by conditional ablation of BMP receptor IA. J. Cell Biol. 163: 609-623.

Kobielak, K., Stokes, N., de la Cruz, J., Polak, L., and Fuchs, E. 2007. Loss of a quiescent niche but not follicle stem cells in the absence of bone morphogenetic protein signaling. Proc. Natl. Acad. Sci. 104: 10063-10068.

Korinek, V., Barker, N., Willert, K., Molenaar, M., Roose, J., Wagenaar, G., Markman, M., Lamers, W., Destree, O., and Clevers, H. 1998. Two members of the Tcf family implicated in Wnt/ $\beta$-catenin signaling during embryogenesis in the mouse. Mol. Cell. Biol. 18: 1248-1256.

Kulessa, H., Turk, G., and Hogan, B.L. 2000. Inhibition of Bmp signaling affects growth and differentiation in the anagen hair follicle. $E M B O ~ J$. 19: 6664-6674.

Leboy, P.S. 2006. Regulating bone growth and development with bone morphogenetic proteins. Ann. N.Y. Acad. Sci. 1068: $14-18$.

Lichti, U., Weinberg, W.C., Goodman, L., Ledbetter, S., Dooley, T., Morgan, D., and Yuspa, S.H. 1993. In vivo regulation of murine hair growth: Insights from grafting defined cell populations onto nude mice. J. Invest. Dermatol. 101: 124S-129S.

Lin, H. 2002. The stem-cell niche theory: Lessons from flies. Nat. Rev. Genet. 3: 931-940.

Lyons, K.M., Pelton, R.W., and Hogan, B.L. 1990. Organogenesis and pattern formation in the mouse: RNA distribution patterns suggest a role for bone morphogenetic protein-2A (BMP-2A). Development 109: 833-844.

Massague, J., Seoane, J., and Wotton, D. 2005. Smad transcription factors. Genes \& Dev. 19: 2783-2810.

Millar, S.E. 2002. Molecular mechanisms regulating hair follicle development. J. Invest. Dermatol. 118: 216-225.

Ming Kwan, K., Li, A.G., Wang, X.J., Wurst, W., and Behringer, R.R. 2004. Essential roles of BMPR-IA signaling in differentiation and growth of hair follicles and in skin tumorigenesis. Genesis 39: 10-25.

Mishina, Y., Hanks, M.C., Miura, S., Tallquist, M.D., and Behringer, R.R. 2002. Generation of Bmpr/Alk3 conditional knockout mice. Genesis 32: 69-72.

Moore, K.A. and Lemischka, I.R. 2006. Stem cells and their niches. Science 311: 1880-1885.

Morris, R.J., Liu, Y., Marles, L., Yang, Z., Trempus, C., Li, S., Lin, J.S., Sawicki, J.A., and Cotsarelis, G. 2004. Capturing and profiling adult hair follicle stem cells. Nat. Biotechnol. 22: $411-417$.
Nishimura, E.K., Jordan, S.A., Oshima, H., Yoshida, H., Osawa, M., Moriyama, M., Jackson, I.J., Barrandon, Y., Miyachi, Y., and Nishikawa, S. 2002. Dominant role of the niche in melanocyte stem-cell fate determination. Nature 416: 854-860.

O'Shaughnessy, R.F., Christiano, A.M., and Jahoda, C.A. 2004. The role of BMP signalling in the control of ID3 expression in the hair follicle. Exp. Dermatol. 13: 621-629.

Peng, Y., Kang, Q., Cheng, H., Li, X., Sun, M.H., Jiang, W., Luu, H.H., Park, J.Y., Haydon, R.C., and He, T.C. 2003. Transcriptional characterization of bone morphogenetic proteins (BMPs)-mediated osteogenic signaling. J. Cell. Biochem. 90: 1149-1165.

Perry, J.M. and Li, L. 2007. Disrupting the stem cell niche: Good seeds in bad soil. Cell 129: 1045-1047.

Rendl, M., Lewis, L., and Fuchs, E. 2005. Molecular dissection of mesenchymal-epithelial interactions in the hair follicle. PLOS Biol. 3: e331. doi: 10.1371/journal.pbio.0030331.

Reya, T. and Clevers, H. 2005. Wnt signalling in stem cells and cancer. Nature 434: 843-850.

Sacchetti, B., Funari, A., Michienzi, S., Di Cesare, S., Piersanti, S., Saggio, I., Tagliafico, E., Ferrari, S., Robey, P.G., Riminucci, M., et al. 2007. Self-renewing osteoprogenitors in bone marrow sinusoids can organize a hematopoietic microenvironment. Cell 131: 324-336.

Schmidt-Ullrich, R. and Paus, R. 2005. Molecular principles of hair follicle induction and morphogenesis. Bioessays 27: 247-261.

Schofield, R. 1978. The relationship between the spleen colonyforming cell and the haemopoietic stem cell. Blood Cells 4: $7-25$.

Shimizu, H. and Morgan, B.A. 2004. Wnt signaling through the $\beta$-catenin pathway is sufficient to maintain, but not restore, anagen-phase characteristics of dermal papilla cells. I. Invest. Dermatol. 122: 239-245.

Solloway, M.J., Dudley, A.T., Bikoff, E.K., Lyons, K.M., Hogan, B.L., and Robertson, E.J. 1998. Mice lacking Bmp6 function. Dev. Genet. 22: 321-339.

Tumbar, T., Guasch, G., Greco, V., Blanpain, C., Lowry, W.E., Rendl, M., and Fuchs, E. 2004. Defining the epithelial stem cell niche in skin. Science 303: 359-363.

Vaezi, A., Bauer, C., Vasioukhin, V., and Fuchs, E. 2002. Actin cable dynamics and Rho/Rock orchestrate a polarized cytoskeletal architecture in the early steps of assembling a stratified epithelium. Dev. Cell. 3: 367-381.

Vainio, S., Karavanova, I., Jowett, A., and Thesleff, I. 1993. Identification of BMP-4 as a signal mediating secondary induction between epithelial and mesenchymal tissues during early tooth development. Cell 75: 45-58.

Walkley, C.R., Olsen, G.H., Dworkin, S., Fabb, S.A., Swann, J., McArthur, G.A., Westmoreland, S.V., Chambon, P., Scadden, D.T., and Purton, L.E. 2007a. A microenvironment-induced myeloproliferative syndrome caused by retinoic acid receptor $\gamma$ deficiency. Cell 129: 1097-1110.

Walkley, C.R., Shea, J.M., Sims, N.A., Purton, L.E., and Orkin, S.H. $2007 b$. Rb regulates interactions between hematopoietic stem cells and their bone marrow microenvironment. Cell 129: 1081-1095.

Weinberg, W.C., Goodman, L.V., George, C., Morgan, D.L., Ledbetter, S., Yuspa, S.H., and Lichti, U. 1993. Reconstitution of hair follicle development in vivo: Determination of follicle formation, hair growth, and hair quality by dermal cells. $J$. Invest. Dermatol. 100: 229-236.

Xie, T. and Spradling, A.C. 2000. A niche maintaining germ line stem cells in the Drosophila ovary. Science 290: 328-330.

Yuhki, M., Yamada, M., Kawano, M., Iwasato, T., Itohara, S., Yoshida, H., Ogawa, M., and Mishina, Y. 2004. BMPR1A 
signaling is necessary for hair follicle cycling and hair shaft differentiation in mice. Development 131: 1825-1833.

Zhang, J., Niu, C., Ye, L., Huang, H., He, X., Tong, W.G., Ross, J., Haug, J., Johnson, T., Feng, J.Q., et al. 2003. Identification of the haematopoietic stem cell niche and control of the niche size. Nature 425: 836-841.

Zhang, J., He, X.C., Tong, W.G., Johnson, T., Wiedemann, L.M., Mishina, Y., Feng, J.Q., and Li, L. 2006. Bone morphogenetic protein signaling inhibits hair follicle anagen induction by restricting epithelial stem/progenitor cell activation and expansion. Stem Cells 24: 2826-2839.

Zhao, G.Q., Liaw, L., and Hogan, B.L. 1998. Bone morphogenetic protein $8 \mathrm{~A}$ plays a role in the maintenance of spermatogenesis and the integrity of the epididymis. Development 125: 1103-1112. 


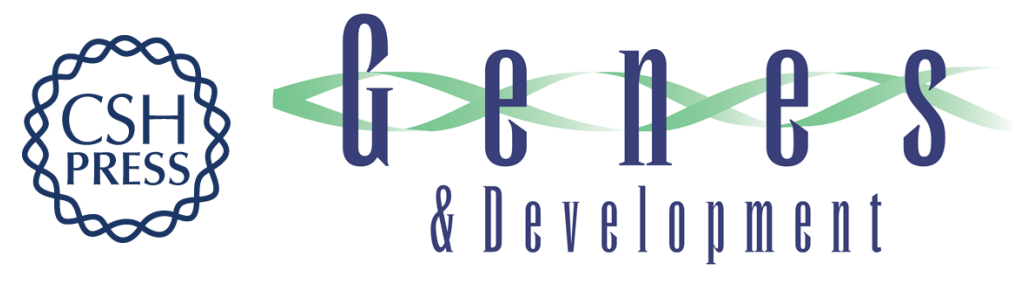

\section{BMP signaling in dermal papilla cells is required for their hair follicle-inductive properties}

Michael Rendl, Lisa Polak and Elaine Fuchs

Genes Dev. 2008, 22:

Access the most recent version at doi:10.1101/gad.1614408

Supplemental http://genesdev.cshlp.org/content/suppl/2008/01/29/22.4.543.DC1
Material

References This article cites 62 articles, 20 of which can be accessed free at: http://genesdev.cshlp.org/content/22/4/543.full.html\#ref-list-1

License

Email Alerting Receive free email alerts when new articles cite this article - sign up in the box at the top Service right corner of the article or click here.

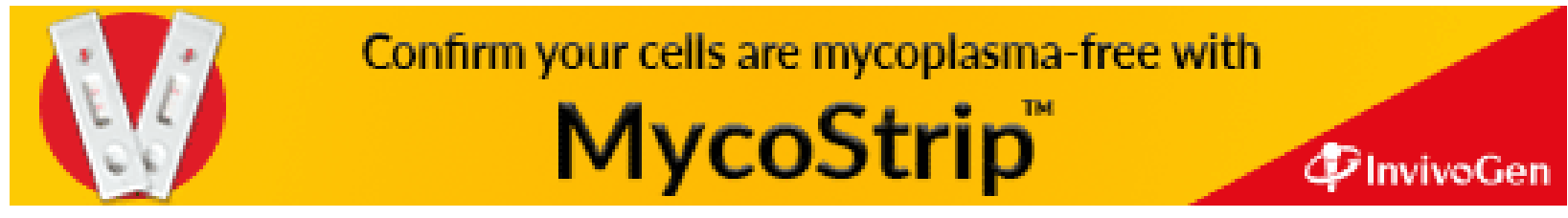

